\title{
Solution of Some Differential Equations by Using Differential Transform Method
}

\author{
P.S. Sutkar \\ Assistant Professor, \\ P. G. Department of Mathematics, \\ N.E.S. Science College, Nanded, India.
}

*Corresponding Author: P.S. Sutkar, Assistant Professor, P. G. Department of Mathematics, N.E.S. Science College, Nanded, India.

\begin{abstract}
In this article, differential transform method (DTM) is applied to solve initial value problems in differential equations. If the system considered has a solution in terms of the series expansion of known functions, this powerful method catches the exact solution. So as to show this capability and robustness, some systems of differential equations are solved as numerical examples.
\end{abstract}

Keywords: Differential transform method; differential inverse transform; ordinary differential equations; Partial differential equation.

\section{INTRODUCTION}

The differential transform was first introduced by Zhou [1] and it is applied to solve differential equation occurred in electrical circuit analysis. The DTM is the method to determine the coefficients of the Taylor series of the function by solving the induced recursive equation from the given differential equation. The updated version of the Taylor series method which is called the differential transform method. It is possible to obtain exact solution of various Initial value problems using the concept of Differential transform method. Initial value problem in the second order differential equation occurs in science and engineering fields. We extend the application of the differential transformation method which is based on Taylor series expansion to obtain analytical approximate solution of the initial value problem.

This paper is organized as, in section 2 the one-dimensional Differential transform method is described and solved some problems, in section 3 two-dimensional Differential transform method is described with example and conclusion is given in section 4 .

\section{Differential Transformation Method}

Definition 1: The differential transformation of the kth derivative of function $\mathrm{u}(\mathrm{x})$ is defined as follows:

$$
U(k)=\frac{1}{k !}\left[\frac{d^{k} u(x)}{d x^{k}}\right]_{x=x_{0}}
$$

and the differential inverse transformation of $\mathrm{U}(\mathrm{k})$ is defined as follows:

$$
u(x)=\sum_{k=0}^{\infty} U(k)\left(x-x_{0}\right)^{k}
$$

In real applications, function $\mathrm{u}(\mathrm{x})$ is expressed by a finite series and equation (2.2) can be

written as

$$
u(x)=\sum_{k=0}^{n} U(k)\left(x-x_{0}\right)^{k}
$$

equation (2.3) implies $\sum_{k=n+1}^{\infty} U(k)\left(x-x_{0}\right)^{k}$ is negligibly small. In fact, $\mathrm{n}$ is decided by the convergence of natural frequency in this study. The following theorems that can be deduced from equation (2.1) and (2.2) are given below 
Theorem 1. If $\mathrm{u}(\mathrm{x})=\mathrm{y}(\mathrm{x}) \pm \mathrm{z}(\mathrm{x})$ then $\mathrm{U}(\mathrm{k})=\mathrm{Y}(\mathrm{k}) \pm \mathrm{Z}(\mathrm{k})$

Theorem 2. If $\mathrm{u}(\mathrm{x})=\mathrm{ay}(\mathrm{x})$, then $\mathrm{U}(\mathrm{k})=\mathrm{aY}(\mathrm{k})$, where $\mathrm{a}$ is a constant.

Theorem 3. If $\mathrm{u}(\mathrm{x})=\left(\frac{d^{m} y(x)}{d x^{m}}\right)$ then $\mathrm{U}(\mathrm{k})=\frac{(m+k) !}{k !} Y(k+m)$

Theorem 4. If $\mathrm{u}(\mathrm{x})=\mathrm{y}(\mathrm{x}) \mathrm{z}(\mathrm{x})$, then $U(k)=\sum_{k_{1}=0}^{k} Y\left(k_{1}\right) Z\left(k-k_{1}\right)$

Theorem 5. If $u(x)=x^{n}$ then $\mathrm{U}(\mathrm{k})=\delta(\mathrm{k}-\mathrm{n}), \delta(k-n)= \begin{cases}1 & k=n \\ 0 & k \neq n\end{cases}$

To demonstrate the method introduced in this study, few examples are solved here.

Example 1. We first start by considering the following equation given by

$u^{\prime \prime}(x)+\frac{4}{x} u^{\prime}(x)+u(x)=10+18 x+x^{2}+x^{3}, 0<x \leq 1$

with initial conditions

$$
\mathrm{u}(0)=0, \mathrm{u}^{\prime}(0)=0 .
$$

By multiplying both sides of equation (2.4) by $\mathrm{x}$ and then taking differential transformation of both sides of the resulting equation using Theorems 1-5, the following recurrence relation is obtained:

$$
\begin{aligned}
& \mathrm{U}(\mathrm{k}+1)=\frac{1}{(k+1)(k+4)} \times\left(10 \delta(k-1)+18 \delta(k-2)+\delta(k-3)+\delta(k-4)-\sum_{l=0}^{k} \delta(l-1) U(k-\right. \\
& \text { l) }
\end{aligned}
$$

By using Equation (2.1) and (2.5), the following transformed initial conditions at $x_{0}=0$ can be obtained:

$$
\begin{aligned}
& \mathrm{U}(0)=0 \\
& \mathrm{U}(1)=0
\end{aligned}
$$

Substituting Equation (2.7) and (2.8) at k=1into equation (2.6), we have

$$
\mathrm{U}(2)=1
$$

Following the same recursive procedure, we find $\mathrm{U}(\mathrm{k}+1)=0, \mathrm{k}=3,4,5, \ldots$ and listing the computation and result corresponding to $\mathrm{n}=3$, we have

$$
\mathrm{U}(3)=1
$$

Using equations (2.7)-(2.10) and the inverse transformation rule in equation (2.3), we get the following solution

$$
\mathrm{u}(\mathrm{x})=x^{2}+x^{3}
$$

Note that for $\mathrm{n}>3$ one evaluates the same solution, which is the exact solution of Equation (2.4) with the initial conditions in equation (2.5).

Example 2 We next consider the following Lane-Emden equation given in [6]

$u^{\prime \prime}(x)+\frac{8}{x} u^{\prime}(x)+x u(x)=x^{5}-x^{4}+44 x^{2}-30 x, 0<x \leq 1$

with initial conditions

$$
\mathrm{u}(0)=0, \mathrm{u}^{\prime}(0)=0
$$

By multiplying both sides of Equation (2.12) by $\mathrm{x}$ and then taking differential transformation of both sides of the resulting equation using Theorems 1-5, we obtain the following recurrence relation

$\mathrm{U}(\mathrm{k}+1)=\frac{1}{(k+1)(k+8)} \times\left(\delta(k-6)-\delta(k-5)+44 \delta(k-3)-30 \delta(k-2)-\sum_{l=0}^{k} \delta(l-2) U(k-l)\right)$

We apply the differential transformation at $x_{0}=0$, therefore, the initial conditions given in equation (2.13) are transformed as follows: 


$$
\begin{aligned}
& \mathrm{U}(0)=0, \\
& \mathrm{U}(1)=0 .
\end{aligned}
$$

Substituting Equation (2.15) and (2.16) at $\mathrm{k}=1$ into Equation (2.14), we have

$$
\mathrm{U}(2)=0 \text {. }
$$

Following the same recursive procedure, we find $\mathrm{U}(\mathrm{k}+1)=0, \mathrm{k}=4,5, \ldots$ and listing the computation and result corresponding to $\mathrm{n}=4$, we have

$$
\begin{aligned}
& \mathrm{U}(3)=-1, \\
& \mathrm{U}(4)=1 .
\end{aligned}
$$

Using Equation (2.15)-(2.19) and the inverse transformation rule in Equation (2.3), we get the following solution:

$$
\mathrm{u}(\mathrm{x})=x^{3}+x^{4}
$$

For $\mathrm{n}>4$, one evaluates that the solution (2.20), which is the exact solution of equation (2.12) under the initial conditions in Equation (2.13).

\section{TWo-Dimensional Differential TRANSFORM METHOD}

The theory to solve partial differential equation by two-dimensional differential transform is given in [4] this section

Definition 2: The two-differential transform of function $\mathrm{w}(\mathrm{x}, \mathrm{y})$ is defined as follows

$$
W(k, h)=\frac{1}{k ! h !}\left[\frac{\partial^{k+h}}{\partial x^{k} \partial y^{h}} w(x, y)\right]_{\substack{x=x_{0} \\ y=y_{0}}}
$$

$\mathrm{w}(\mathrm{x}, \mathrm{y})$ is the original function and $\mathrm{W}(\mathrm{k}, \mathrm{h})$ is the transformed function .

Definition 3: The differential inverse transformation of $\mathrm{W}(\mathrm{k}, \mathrm{h})$ is defined as follows:

$$
\begin{gathered}
w(x, y)=\sum_{k=0}^{\infty} \sum_{\mathrm{h}=0}^{\infty} \mathrm{W}(\mathrm{k}, \mathrm{h}) \mathrm{x}^{\mathrm{k}} \mathrm{y}^{\mathrm{h}} \\
w(x, y)=\sum_{k=0}^{\infty} \sum_{\mathrm{h}=0}^{\infty} \frac{1}{k ! h !}\left[\frac{\partial^{k+h}}{\partial x^{k} \partial y^{h}} w(x, y)\right]_{\substack{x=x_{0} \\
y=y_{0}}} \mathrm{x}^{\mathrm{k}} \mathrm{y}^{\mathrm{h}}
\end{gathered}
$$

Equation (3.3) implies that the concept of two-dimensional differential transform is derived from twodimensional Taylor series expansion. The lower case letters represent the original functions and upper case letters stands for the transformed functions. The transformed function follows basic mathematical operations $[4,5]$.

Theorem 6.If $\mathrm{w}(\mathrm{x}, \mathrm{y})=\mathrm{u}(\mathrm{x}, \mathrm{y}) \pm \mathrm{v}(\mathrm{x}, \mathrm{y})$ then $\mathrm{W}(\mathrm{h}, \mathrm{k})=\mathrm{U}(\mathrm{h}, \mathrm{k}) \pm \mathrm{V}(\mathrm{h}, \mathrm{k})$

Theorem 7.If $\mathrm{w}(\mathrm{x}, \mathrm{y})=\lambda \mathrm{u}(\mathrm{x}, \mathrm{y})$ then $\mathrm{W}(\mathrm{h}, \mathrm{k})=\lambda \mathrm{U}(\mathrm{h}, \mathrm{k})$

Theorem 8.If $w(x, y)=\frac{\partial u(x, y)}{\partial x}$ then $\mathrm{W}(\mathrm{h}, \mathrm{k})=(\mathrm{k}+1) \mathrm{U}(\mathrm{k}+1, \mathrm{~h})$

Theorem 9.If If $w(x, y)=\frac{\partial u(x, y)}{\partial y}$ then $\mathrm{W}(\mathrm{h}, \mathrm{k})=(\mathrm{h}+1) \mathrm{U}(\mathrm{k}+1, \mathrm{~h})$

Theorem 10.If $w(x, y)=\frac{\partial^{r+s} u(x, y)}{\partial x^{r} \partial y^{s}}$ then $\mathrm{W}(\mathrm{k}, \mathrm{h})=(\mathrm{k}+1)(\mathrm{k}+2) \ldots(\mathrm{k}+\mathrm{r})(\mathrm{h}+1)(\mathrm{h}+2) \ldots(\mathrm{h}+\mathrm{s}) \mathrm{U}(\mathrm{k}+\mathrm{r}, \mathrm{h}+\mathrm{s})$

Theorem 11.If $\mathrm{w}(\mathrm{x}, \mathrm{y})=\mathrm{u}(\mathrm{x}, \mathrm{y}) \mathrm{v}(\mathrm{x}, \mathrm{y})$ then $\mathrm{W}(\mathrm{k}, \mathrm{h})=\sum_{r=0}^{k} \sum_{s=0}^{h} U(r, h-s) V(k-r, s)$

Theorem 12.If $w(x, y)=x^{m} y^{n}$ then $w(k, h)=\delta(k-m, h-n)=\delta(k-m) \delta(h-n)$ where

$$
\delta(k-m)=\left\{\begin{array}{l}
1, k=m \\
0, k \neq m
\end{array} \quad \delta(h-n)=\left\{\begin{array}{l}
1, h=n \\
0, h \neq n
\end{array}\right.\right.
$$

Example 3. Consider the partial differential equation [2]

$$
\frac{\partial w(x, t)}{\partial t}\left[\frac{\partial w(x, t)}{\partial x}\right]^{2}-1=0,
$$

with initial condition $\mathrm{w}(\mathrm{x}, 0)=\mathrm{x}$ 
Whose solution [2] is $\mathrm{w}(\mathrm{x}, \mathrm{t})=\mathrm{x}+\mathrm{t}$

On taking two dimensional differential transform of (3.4) and by using the theorem (6-12), we have

$$
\sum_{r=0}^{k} \sum_{s=0}^{h}(k-r+1)^{2}(h-s+1)(W(k-r+1, s))^{2} W(r, h-s+1)-\delta(k, h)=0
$$

Using equation (3.2) and initial condition (3.5) we have

$$
\begin{aligned}
& \mathrm{W}(\mathrm{i}, 0)=0, \mathrm{i}=0,2,3, \ldots \mathrm{m} \\
& \mathrm{W}(1,0)=1
\end{aligned}
$$

Substituting equation (3.7) and (3.8) into (3.6) and by recursive method [3,4] the results corresponding to $\mathrm{m} \rightarrow \infty$ are listed

$$
\mathrm{W}(0,1)=1
$$

and all others are zero, substituting all $\mathrm{W}(\mathrm{k}, \mathrm{h})$ into (3.3), we obtain series solution as follows

$\mathrm{w}(\mathrm{x}, \mathrm{t})=\mathrm{x}+\mathrm{t}$

\section{CONClusion}

In this study, the differential transformation method is implemented to the Ordinary Differential Equations and partial differential equations as singular initial value problems. Differential equations are solved and exact solutions are obtained by using differential transformation method. It is shown that differential transformation method is a very fast convergent, precise and cost efficient tool for solving the ordinary differential equations and partial differential equations.

\section{REFERENCES}

[1] Zhou J. K., Differential Transformation and Its Applications for electrical Circuits (in Chinese), Huazhong University Press, Wuhan, China, 1986.

[2] ZauDerer E., Partial Differential Equations of Applied Mathematics, Wiley, New York,1989

[3] Chen C.K.,S-H Ho, Application of differential transformation to eigenvalue problems, Applied Mathematics and Computation.79,(1996) ,173-188

[4] Chen C.K., Solving partial differential equations by two-dimensional differential transform method, Applied Mathematics and Computation 106, 171-179,1999.

[5] Wazwaz A.M., A new method for solving singular initial value problems in the second-order ordinary differential equations, Applied Mathematics and Computation 128, 45-57, 2002.

[6] Erturk V. S., S. Momani, Comparing numerical methods for solving fourth-order boundary value problems, Applied Mathematics and Computation (2007), doi: 10.1016/ j.amc.2006.11.075.

\section{AUTHOR'S BIOGRAPHY}

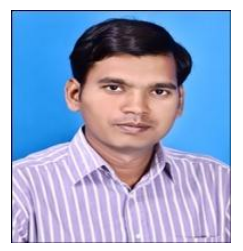

Prashant S. Sutkar, is working as assistant professor in post graduate department of Mathematics, NES science College, Nanded, India. He is interested in Differential Equation, Heat transfer, mass transfer, nanofluids.

Citation: P.S. Sutkar, "Solution of Some Differential Equations by Using Differential Transform Method s ", International Journal of Scientific and Innovative Mathematical Research, vol. 5, no. 5, p. 4, 2017., http://dx.doi.org/10.20431/2347-3142.0505003

Copyright: (C) 2017 Authors. This is an open-access article distributed under the terms of the Creative Commons Attribution License, which permits unrestricted use, distribution, and reproduction in any medium, provided the original author and source are credited. 